\title{
Nutrition in paediatric human immunodeficiency virus infection
}

\author{
Tracie L. Miller \\ University of Rochester Medical Center, Children's Hospital at Strong, 601 Elmwood Avenue, Box 667, \\ Rochester, NY 14642, USA
}

\begin{abstract}
The nutritional condition of children with human immunodeficiency virus (HIV) infection continues to be a problem both in developed and developing countries. HIV-infected children grow below normal standards in both height and weight when compared with HIV-exposed noninfected children. These patterns persist over time. It is possible that acute infectious episodes and increased HIV viral burden contribute to decrements in all growth variables. Potential aetiologies for abnormal growth include inadequate dietary intake, gastrointestinal malabsorption, increased energy utilization and psycho-social problems. It is likely that all these factors contribute to the growth problems of these children to some extent. With the development of protease inhibitor anti-retroviral therapy and highly-active anti-retroviral treatment regimens, children with HIV infection in developed countries are living longer with a chronic illness. New nutritional problems have arisen with the development of the fat redistribution syndrome or lipodystrophy. Emerging problems are now being recognized, with the development of insulin resistance and truncal obesity which may potentially lead to premature cardiovascular disease.
\end{abstract}

Human immunodeficiency virus: Acquired immune deficiency syndrome: Nutritional status: Malnutrition: Children

\section{The scope of paediatric human immunodeficiency virus infection}

The human immunodeficiency virus (HIV) infection was first discovered in 1984 (Gallo et al. 1984), although the clinical condition known as the acquired immune deficiency syndrome (AIDS) was described several years earlier. Soon thereafter, perinatally-acquired HIV infection was reported (Falloon et al. 1989). Since its initial discovery there has been a worldwide increase in the incidence of perinatallyacquired HIV infection, which has stabilized somewhat in the USA and Western Europe, although it continues to be a major health problem worldwide, especially in Asia and Africa. Paediatric HIV infection is the leading cause of death in children worldwide, and is the fourth to seventh leading cause of death in the USA for children aged 1-4 years. There have been over 9000 paediatric AIDS cases reported in the USA and over 7000 paediatric AIDS cases in Europe (Pizzo \& Wilfert, 1998). There is a greater prevalence in Western Europe, with the exception of the Romanian orphanages. Africa and Asia account for the majority of paediatric AIDS cases worldwide.
The incidence of perinatally-acquired HIV infection in developed countries is decreasing due largely to the combined effects of better prenatal screening and zidovudine treatment of HIV-infected women during pregnancy (Connor et al. 1994). HIV transmission from mother-to-infant has dropped from $20-25 \%$ to 6-7 \%. As a result of improved screening methods and aggressive early treatment paediatric HIV infection has become a chronic illness with increased life expectancy. Protease-inhibitor and highly-active anti-retroviral therapies account for many of the advances.

There has been a long-held association between the effects of nutrition and immune function. Clinically, Pneumocystis carinii infection was first reported in otherwise healthy, but significantly malnourished, children in developing countries (Hughes et al. 1974). Kaposi's sarcoma was also first reported in children who were malnourished but had no other underlying chronic medical conditions (Centers for Disease Control. Task Force on Kaposi's Sarcoma and Opportunistic Infections, 1982). In addition, improved nutrition has shown positive influences on health in other chronic illnesses such as cystic fibrosis and cancer. 
The cellular effects of HIV and protein-energy malnutrition are quite similar. There are decreases in CD4 T-cells with reversal of the CD4:CD8 value in both conditions. There is also suppression of delayed hypersensitivity and abnormal B-cell responses. Complement levels are changed (Scrimshaw et al. 1968; Chandra \& Newbuerne, 1977). Since both conditions, protein-energy malnutrition and HIV, can affect immunity in the same way, it is likely that a child with both protein-energy malnutrition and HIV would have worse outcomes than those with either condition alone.

The prevalence of malnutrition in HIV-infected children is considerable, and will vary between centres and countries depending on the medical care that is available for that child. In the USA up to $30-50 \%$ of children followed in HIV programmes have evidence of protein-energy malnutrition. In developing countries of Africa malnourished children admitted to hospitals have a much greater chance of being HIV-infected than not, with up to $40-50 \%$ of malnourished patients seen in hospital programmes being newly diagnosed with HIV (Mgone et al. 1991). The wasting syndrome of HIV-infected adults and children is considered an AIDS-defining illness. Wasting is defined as greater than $10 \%$ weight loss over 2 months. The correlation between morbidity, mortality and nutrition in patients with HIV infection is becoming increasingly well documented. Kotler et al. (1989) reported at an early stage in the research that there is a good correlation between body cell mass and timing of death in patients with AIDS. This finding may be no different from that found in other nutritional states where patients who are below $55 \%$ of normal lean body mass are at great risk for mortality. Other reports in adults have shown that weight loss of greater than $20 \%$ significantly influences median survival; with $10 \%$ weight loss the median survival was $520 \mathrm{~d}$, and with greater than $20 \%$ weight loss the survival was $48 \mathrm{~d}$ (Greene, 1988). Survival of AIDS patients has been correlated with baseline serum albumin levels. Levels less than $25 \mathrm{mg} / 1$ have been correlated with timing of death (Chlebowski et al. 1989).

In the present paper the current knowledge on the growth and body composition of HIV-infected children in developed countries will be reviewed, with emphasis on aetiological factors associated with malnutrition. These factors will include energy intake, metabolism and gastrointestinal absorption. Finally, interventions and new therapeutic modalities that have potential or are currently having an impact on the nutritional status of HIV-infected children will be reviewed.

\section{Growth and body composition of human immunodeficiency virus-infected children}

A large multicentre US study of pulmonary and cardiac complications of HIV-infected children has evaluated growth (Pitt et al. 1998). The primary intent of the study was to determine the prevalence, incidence and types of cardiovascular and pulmonary disease in the fetus, newborn infant, and child with vertically-transmitted HIV infection, and to describe the course and outcome of these disorders. Another aim was to determine whether early detection of cardiovascular and pulmonary complications associated with HIV could be accomplished using sensitive cardiological and pulmonary techniques, and also investigate cofactors of HIV infection which could be associated with cardiovascular and pulmonary abnormalities. Cofactors included pulmonary or systemic bacterial or viral infections, co-infections with Epstein Barr and cytomegalovirus, immune markers, primary treatment for HIV infection, perinatal events and growth failure. Children were divided into two groups. Group 1 included a cohort of 205 HIV-infected children who were diagnosed or enrolled at greater than $28 \mathrm{~d}$ of age. Group 2 included a group of 611 children who were born to HIV-infected women. Ninety-two of these children were HIV infected, the remaining children were a non-infected cohort who were followed longitudinally. This study showed that over a 5-year period birth weights were similar between infected and non-infected groups, although within the first 1-2 months of life the weights and heights of HIV-infected children declined when compared with those for the non-infected cohort. Once HIV-infected children deviated from the non-infected group these differences persisted, but did not increase over time. HIV-infected children had lower weight-for-height Z-scores, although much of the time these differences were not statistically significant. This study also looked at factors that were associated with failure to thrive in this group of ninety-two children. 'Crack' (a crystalline form of cocaine which is either inhaled or smoked) and cocaine used during pregnancy gave a 3.2-fold increased risk of growth failure as defined by a weight $\mathrm{Z}$-score of $<-2 \cdot 0$. In addition, a lower CD4 count per $1 \mathrm{SD}$ decrease also showed a $2 \cdot 1$-fold increased risk for growth failure. Time to any pneumonia gave an 8.8-fold increased risk for growth failure, and antiretroviral therapy (non-protease inhibitor) was associated with a 2.8-fold increased relative risk (TL Miller, KA Easley, W Zhang, EJ Orav, D Bier, R Deckelbaum, E Luder, A Ting, M Schluchter, W Shearer, JH Vargas and SE Lipshulz, unpublished results).

In another US multicentre study, the Women and Infants Transmission Study, similar analysis evaluated longitudinal growth in perinatally-infected children (Moye et al. 1996). HIV-infected children were $0.2 \mathrm{~kg}$ lighter and $4.1 \mathrm{~mm}$ shorter than the non-infected children. The longitudinal analysis also showed HIV-infected children with similar birth weights, but within the first 1-3 months reached a stable, but lower, weight and length.

We have been prospectively evaluating growth and nutritional indices over the last several years at Children's Hospital, Boston, MA, USA and the University of Rochester Medical Center, MN, USA (Miller et al. 1997a). An evaluation of growth and body composition of seventy-nine HIV-infected children, twenty-one children with AIDS and 113 controls, before protease-inhibitor therapy, showed that weight Z-scores of HIV-infected children and children with AIDS at first evaluation were not significantly different, although there were significant differences between both the HIV-positive patients and patients with AIDS and the control patients $(P<0.05$; Table 1$)$. Patients with AIDS were stunted, with lower height $\mathrm{Z}$-scores compared with the HIV-positive patients. Weight-for-height was also higher in the HIV and AIDS patients. We evaluated triceps skinfold thicknesses (TSF) and found that there was no significant 
Table 1. Clinical characteristics of a cohort of human immunodeficiency virus (HIV)-infected and exposed children (Mean values with their standard errors)

\begin{tabular}{|c|c|c|c|c|c|c|}
\hline & \multicolumn{2}{|c|}{ AIDS (n21) } & \multicolumn{2}{|c|}{ HIV-positive ( $n$ 79) } & \multicolumn{2}{|c|}{ Control (n 113) } \\
\hline & Mean & SE & Mean & SE & Mean & SE \\
\hline Age (months) & 35 & $5 \cdot 0$ & 31 & $2 \cdot 6$ & $16^{*}$ & $1 \cdot 16$ \\
\hline $\operatorname{Sex}(M: F)$ & $1: 1 \cdot 6$ & & $1: 1$ & & $1: 1 \cdot 1$ & \\
\hline Absolute CD4 count (cells $/ \mathrm{mm}^{3}$ ) & $569(n 19)$ & 182 & $1150(n 71) \dagger$ & 94.4 & & \\
\hline Percentage of normal CD4 count & 21 & $16 \cdot 1$ & $42 \cdot 7$ & $22 \cdot 2$ & & \\
\hline $\begin{array}{l}\text { Percentage receiving anti-retroviral } \\
\text { medications }\end{array}$ & $67(14$ of 21$)$ & & $29(22$ of 75$) \dagger$ & & & \\
\hline Weight Z-score & $-0 \cdot 76$ & 0.24 & -0.44 & $0 \cdot 13$ & -0.24 & $0 \cdot 105$ \\
\hline Height Z-score & $-1 \cdot 77$ & $0 \cdot 22$ & $-0 \cdot 79 \dagger$ & $0 \cdot 11$ & $-0 \cdot 43^{*}$ & $0 \cdot 10$ \\
\hline Weight-for-height Z-score & 0.54 & 0.23 & 0.14 & $0 \cdot 12$ & 0.09 & $0 \cdot 10$ \\
\hline Triceps skinfold thickness (\%)§ & 37 & $5 \cdot 45$ & 39 & $2 \cdot 80$ & 35 & $2 \cdot 35$ \\
\hline Arm muscle circumference (\%)§ & 54 & $6 \cdot 02$ & 56 & $3 \cdot 10$ & 62 & $2 \cdot 60$ \\
\hline Percentage with diarrhoea & $33(7$ of 21$) \ddagger$ & & $8(6$ of 75$)$ & & $9(10$ of 109$)$ & \\
\hline Percentage with vomiting & $0(0$ of 20$)$ & & $3(2$ of 74$)$ & & $5(5$ of 106$)$ & \\
\hline
\end{tabular}

AIDS, acquired immune deficiency syndrome.

Mean values were significantly different from those for AIDS and HIV-positive groups: ${ }^{*} P<0.05$.

Mean values were significantly different from those for AIDS group: $\uparrow P<0.05$.

Mean values were significantly different from those for HIV-positive and control groups: $\ddagger P<0.05$.

$\S$ Based on percentile for age and sex (according to established standards).

difference between groups. Arm muscle circumference (AMC) was reduced in the HIV-positive patients compared with control patients. Other characteristics of the cohort are shown in Table 1. Longitudinal changes in anthropometry over time showed that weight Z-scores for both HIV and AIDS patients decreased over time, although not significantly. Height Z-scores showed a decline over time in the HIV-positive group. Weight-for-height Z-scores were stable over time, as was TSF. AMC decreased in both the HIV-positive and AIDS patients, but more so in the HIV-positive children, with a $1.8 \%$ decrease per year noted. This study evaluated predictors of changes in weight and lean body mass in these children in a controlled analysis. Energy intake had a significant impact on weight over time, with diarrhoea, and anti-retroviral therapy (non-protease inhibitor) having a detrimental effect on weight. Increasing age predicted a loss of lean body mass, and female gender was protective of loss of lean body mass. We found that anti-retroviral therapy also had a detrimental effect on lean body mass.

In summary, various growth patterns have been described (Miller et al. 1993; Saavedra et al. 1995; The European Collaborative Study, 1995; Berhane et al. 1996; Henderson et al. 1996; Arpadi et al. 1998), although in developed countries it appears that HIV-infected children have stable weight patterns, although below those of age-matched controls. Difference in growth patterns probably reflects the spectrum of disease in children with HIV, with many confounding factors, including treatment status and co-morbidities. There is an early decline in weight and height. One pattern of early linear stunting with a normal weight: height is common. Progressive wasting with low weights and heights has been associated with infectious and prenatal factors. In addition, gender may also influence nutritional status. These growth patterns underscore the importance of trying to control for the multitude of confounding factors that can influence the growth of children with HIV infection.

\section{Factors affecting nutritional status of human immunodeficiency virus-infected children}

There are several potential factors that could influence the nutritional state of any child with chronic illness. Included among these factors are energy intake, gastrointestinal absorptive capacity, metabolic pathways and psycho-social factors. Since HIV is a spectrum of disease, it is likely that all these factors contribute to the nutritional health of HIV-infected children.

\section{Dietary intake}

Although there are many potential aetiologies for inadequate energy intakes of HIV-infected children, there is little data to support this theory (Table 2). Primary anorexia associated with chronic illness can be caused by chemical mediators such as cytokines. Children with HIV infection may have dental problems or oropharyngeal infections that could affect their ability to consume adequate energy (Katz et al. 1993). In addition, Candida albicans, herpes, and cytomegalovirus oesophagitis or infections of the upper gastrointestinal tract can also result in pain and discomfort when eating. A retrospective study of gastrointestinal endoscopies have also shown a high incidence of peptic disease in HIV-infected children (Miller et al. 1997b). All medications have potential side effects and toxicities. Children with HIV are required to take a multitude of medications that often have gastrointestinal toxicities or side effects which can result in vomiting, nausea and anorexia. Pancreatitis has been described in HIV-infected children, 
Table 2. Aetiology of abnormal dietary intake in children infected with human immunodeficiency virus

Periodontal or gingival disease
Opportunistic infections of the upper gastrointestinal tract
Candida albicans (thrush or Candidal oesophagitis)
Herpes simplex virus
Cytomegalovirus
Idiopathic oral or oesophageal ulcers
Dysguesia
Opportunistic infections
Micronutrient deficiencies
Peptic disease
Gastro-oesophageal reflux
Gastritis or duodenitis
Helicobacter pylori
Hepatobiliary disorders
Cholangitis
Pancreatitis
Encephalopathy
Depression

and can be associated with abdominal discomfort and vomiting which could lead to poor oral intake (Miller et al. 1992; Butler et al. 1993). Last, children with HIV may develop HIV encephalopathy with dyscoordinated swallowing. Children in this condition are not able to physically consume energy because of neurological deficits, and often it is dangerous because of the risk of aspiration.

We have collected dietary records of children who are HIV-positive, children with AIDS and controls (Miller et al. 1997a). In this study of over 700 food records, we found that total energy intake is similar across groups, as were the intakes of the protein, carbohydrate and fat. The average intake was $115 \%$ of the recommended dietary allowance (RDA; National Research Council, 1989) for age and gender and $75 \%$ of children consumed $100 \%$ of the RDA or more. Dietary intake over time was stable in all groups. We determined the influence of the dietary intake on weight across quartiles and found that diets of $115 \%$ of the RDA had the greatest effect and influence on weight Z-score (Miller et al. 1997a). Of the cohort, $25 \%$ consumed $160 \%$ of the RDA or more. Other studies on the dietary intake of these children are limited, although results are similar, with normal dietary and micronutrient intakes (Zuin et al. 1994; Henderson et al. 1997). In general, limited data show that low energy intake does not fully explain the nutritional problems of children with HIV in developed countries.

\section{Gastrointestinal malabsorption}

The pathogenesis of the gastrointestinal malabsorption can be related to ongoing enteric infections that damage the small intestinal brush border. Malnutrition alone, if severe, can cause villous atrophy and inflammation. This damage can result in a secondary malabsorptive process. Children with HIV are also at risk of small intestinal overgrowth because of the immune deficiency. Hypochlorhydria has been described in patients with HIV infection, which can also promote small intestinal overgrowth (Lake-Bakaar et al. 1988). Furthermore, iatrogenic acid-blocking therapy can also cause small intestinal overgrowth by diminishing the acid barrier of the stomach. Regardless of the cause, small intestinal overgrowth can lead to an enteropathy and malabsorption. Last, pancreatic and hepatobiliary insufficiency, which occasionally can be seen in children with HIV infection, can lead to malabsorption.

An HIV enteropathy was initially described by Kotler et al. (1984) and other workers, in the 1980s (Ullrich et al. 1989). This entity is defined by villous blunting and atrophy, hypercellular lamina propria and the absence of an enteric infection. HIV enteropathy was initially, and possibly still is, considered a separate entity that could contribute to gastrointestinal malabsorption. However, this concept has been challenged due to the more sensitive detection of unusual micro-organisms that could cause a secondary enteropathy similar to 'HIV enteropathy'.

We (Miller et al. 1991) and other workers (Yolken et al. 1991) have evaluated the ability of children to absorb lactose. Non-physiological lactose malabsorption was found in $40 \%$ of young HIV-infected children without an enteric infection. Lactose malabsorption can also be associated with small intestinal pathogens such as Cryptosporidium, Giardia lamblia or Rotavirus. We found in our study that lactose malabsorption was not always associated with diarrhoea or nutritional status. This finding has been confirmed by other workers, although in some studies a strong relationship has been shown between lactose malabsorption, diarrhoea, and nutritional status (Yolken et al. 1991). We also found that children with HIV have abnormal D-xylose absorption, which was often associated with an enteric infection (Miller et al. 1991). Other workers (The Italian Pediatric Intestinal/HIV Study Group, 1993) have found fat malabsorption that may reflect intestinal dysfunction, hepatic or pancreatic insufficiency. It is possible that gastrointestinal malabsorption is responsible, in part, for nutritional problems, especially for children with more advanced disease.

\section{Altered metabolism}

Metabolism is related to energy utilization. In patients with stable weight energy utilization should approximate energy intake. Thus, total energy expenditure, the energy required for daily living, should be equal to resting energy expenditure (REE) plus the energy required for daily activities plus the thermic effect of eating. Studies of REE in children with HIV are few (Henderson et al. 1998). In adults, REE is increased in asymptomatic stages of HIV infection (Hommes et al. 1991; Suttmann et al. 1993) and will increase progressively with increased stage and with active infections. Studies of REE in children, although limited, have not found large differences between HIV-infected and control patients (Henderson et al. 1998). We have preliminary results for twenty-one children that show REE per unit lean body mass is not significantly different between controls and HIV-infected children, although there was a trend towards a greater REE in HIV-infected children than in control children. There were significant positive correlations between REE and CD4 counts and lean body mass. Correlations between cardiac 
and nutritional indices can indirectly reflect metabolic rates (Miller et al. 1997c). In one study weight Z-scores and AMC were inversely related to heart rate in HIV-infected children. The typical cardiovascular response to malnutrition is bradycardia. This paradoxical relationship suggests that metabolic factors are driving cardiovascular responses, irregardless of nutritional state, and could lead to high metabolic rates.

There have been no reported studies on total energy expenditure of HIV-infected children. We have preliminary results using the doubly-labelled-water technique (TL Miller, C Duggan, B Mawn and SL Gorbach, unpublished results). The seven children studied were relatively well, with most children being CDC stage B (CDC paediatric HIV classification ranges from $\mathrm{N}$ (no HIV-related symptoms) to $\mathrm{A}, \mathrm{B}$ and $\mathrm{C}$ (least to greatest HIV-related symptoms respectively); Centers for Disease Control, 1993). Food records $(3 \mathrm{~d})$ revealed that these children consumed about $114 \%$ of the RDA, similar to that found in our previous studies, and their total energy expenditure, as determined by doubly-labelled water, was $102 \%$ of the RDA. Thus, it appeared that these children had normal metabolic rates and were consuming adequate energy. These findings may not be applicable to children with more advanced disease, who are at greatest risk for weight loss. Future studies are needed to determine energy utilization in more advanced HIV stages.

Potential mediators of metabolism and cachexia include pro-inflammatory cytokines such as tumour necrosis factor $\alpha$, interleukins $1 b$ and 6 , and interferon $\alpha$. These cytokines may induce synthesis of acute-phase reactants, which in turn use energy substrates ineffectively. Cytokine data are conflicting, and there are intrinsic difficulties in measuring these chemicals. Results can differ with stimulated $v$. serum assays. The effects of cytokines are typically paracrine, and serum levels may not truly reflect the activity of these chemicals at the tissue level. In addition, cytokines may be released in a pulsatile fashion, such that determination of levels at one point in the day may be very different from those at another point in the day. Murine models have shown that infusions of tumour necrosis factor have produced significant wasting and anorexia (Flores et al. 1989). There have been few studies looking at growth and body composition measurements while correlating them with cytokine levels in children. We have prospectively looked at levels of interleukins $1 \mathrm{~b}$ and 6 and tumour necrosis factor $\alpha$ in children with HIV (TL Miller, C Duggan, B Mawn and SL Gorbach, unpublished results). We have preliminary cross-sectional reports on fifty-two patients with HIV. We initially suspected that as children became more wasted, the nutritional indices would be inversely related to stimulated cytokine levels. Paradoxically, we found a positive relationship between growth and cytokine levels. We found that these pro-inflammatory cytokines were correlated positively with CD4 counts, weights and heights. This positive correlation is more typically found in malnutrition, where the ability to produce cytokines is diminished. Our cohort were well outpatients, and did not have active opportunistic infections. It will be important to evaluate cytokines as children develop active infections and weight loss.

\section{Interventions that improve growth and body composition}

\section{Fat redistribution syndrome and protease-inhibitor therapy}

Over the past several years there have been dramatic advances in anti-retroviral therapy that have resulted in improved survival for all patients with HIV infection. The viral load of patients on protease inhibitors can reach nondetectable levels. Improved CD4 counts are also possible. As protease-inhibitor therapy becomes more routine, a clinical entity called the fat redistribution syndrome or lipodystrophy has emerged. This syndrome has been described in patients receiving highly-active anti-retroviral therapy, but has also been found in patients who have not been exposed to highly-active anti-retroviral therapy (Dube et al. 1997; Carr et al. 1998a,b; Striker et al. 1998). Patients develop a dorsocervical fat pad, abdominal adiposity, increased breast size in women, facial and extremity wasting and wasting of the buttocks. Weight can be stable or increased in adults with HIV. Biochemically, laboratory features include hyperlipidaemia with increased triacylglycerol and total cholesterol levels. Increased LDL and decreased HDL levels have been observed. Patients have also developed insulin resistance, with normal to increased serum glucose, increased insulin levels, increased C-peptides, and abnormal glucose-tolerance tests. Although clinically this syndrome is similar to Cushing's syndrome, serum cortisol levels and dexamethasone suppression tests are normal. In adult patients prevalence studies have shown that after 10 months of protease-inhibitor therapy up to $50 \%$ of patients have self reported lipodystrophy. A recent study (Carr et al. 1999) reported on 113 patients who received protease-inhibitor therapy for a mean of 21 months and forty-five HIV-infected patients who had never been treated with protease inhibitors. There was $98 \%$ concordance between patients' reports of lipodystrophy and physical examination. Of the protease-inhibitor recipients $83 \%$ reported lipodystrophy symptoms, while the corresponding value for the treatment-naïve patients was $4 \%$. Using dual-energy X-ray absorptiometry as a measure of body composition, investigators found declining total body fat on protease-inhibitor therapy. Lower body fat was independently associated with longer duration of proteaseinhibitor therapy, and lower body weight before therapy and more severe lipodystrophy was associated with higher previous and current triacylglycerol and C-peptide concentrations, and less peripheral and greater central fat. Body fat declined by a mean of $1.2 \mathrm{~kg}$ over 8 months for protease-inhibitor recipients. The prevalence of hyperlipidaemia remained stable over time, with $74 \%$ of the protease-inhibitor-treated patients and $28 \%$ of the treatment-naïve patients having abnormal lipid levels. Impaired glucose tolerance occurred in $16 \%$ of the protease-inhibitor-recipient patients and diabetes in $7 \%$. These authors concluded that the diagnosis of lipodystrophy is aided by the combination of physical examination, patients' self rating, body fat measurements and fasting triacylglycerol and C-peptide levels. Baseline weight before therapy, fasting triacylglycerols and C-peptide concentrations and therapy duration predict lipodystrophy severity. Lipodystrophy was common and progressive after almost 2 
years of protease-inhibitor therapy, but was not usually severe.

We have recently looked at the effect of proteaseinhibitory therapy on growth and body composition in children with HIV infection (TL Miller, C Duggan, B Mawn and SL Gorbach, unpublished results). We studied sixtyseven children who had been exposed to protease inhibitors. We followed nutritional indices before and after proteaseinhibitor therapy. Up to $25 \%$ of the cohort had AIDS and most were vertically infected with HIV. A univariate analysis of weights, heights and body composition measures before or after protease-inhibitor therapy found that there was an improvement in weight and weight-for-height Z-score while on protease-inhibitor therapy. Although height $Z$-score improved, this improvement was not significant in the univariate analysis. There were no significant differences in AMC and TSF. In the multivariate analysis controlling for factors such as CDC stage (Centers for Disease Control, 1993), age, gender and disease severity, we found that protease inhibitors had a significant effect on weight Z-score and a borderline effect on height Z-score. There was also an improvement in weight-for-height Z-score. AMC also improved, although there was no effect on TSF. Thus, protease-inhibitor therapy can influence nutritional outcomes, and for the first time there is an intervention with positive effects on height. Further studies are needed to quantify the lipid abnormalities and fat regionalization in children.

\section{Megestrol acetate}

Megestrol acetate, a synthetic progesterone derivative, can affect the weight of HIV-infected children (Clarick et al. 1997). There have been several reports of adults showing improvements in both fat and lean body mass (Oster et al. 1994; Von Roenn et al. 1994). This effect can take several months to occur. There have been anecdotal reports of development of diabetes on megestrol acetate, as well as fluid retention (Henry et al. 1992). We recently evaluated seven HIV-infected children who were treated with megestrol acetate for an average of 14 months (TL Miller, C Duggan, B Mawn and SL Gorbach, unpublished results). We found that there was significant improvement in weight, although there was no appreciable effect on height. TSF increased as well as AMC. Energy intake was no different between groups.

\section{Impact of gastrostomy tube feedings}

Supplemental enteral feedings have improved nutrition in many chronic conditions. We determined whether gastrostomy tube feedings would affect weight, height, lean body mass, immune indices, morbidity and mortality (Miller et al. 1995). Twenty-six children who received gastrostomy tube feedings were evaluated before and after therapy. Of these patients, $73 \%$ had AIDS at the time of gastrostomy tube placement, and all of them were symptomatic. We found that weight $\mathrm{Z}$-scores before therapy were -1.6 and had decreased to $-2 \cdot 2$ on initiation of nasogastric feedings. Gastrostomy tube feedings significantly improved weight Z-scores back to baseline approximately 5 months after their initiation. We found positive correlations between improvement in weight Z-score and increased TSF. We found no increase in lean body mass. Energy intake improved, as these children were taking $460 \mathrm{~kJ}(110 \mathrm{kcal}) / \mathrm{kg}$ per $\mathrm{d}$ at baseline, which with the initiation of gastrostomy tube feedings improved to $790 \mathrm{~kJ}(189 \mathrm{kcal}) / \mathrm{kg}$ per $\mathrm{d}$. Significant predictors of response to gastrostomy tube feedings included better CD4 counts at their initiation and lower weight-for-height $\mathrm{Z}$-scores at baseline. These findings suggest that early intervention in the context of acute weight loss has the best promise for improving weight. Children with the greatest improvement in weight spent less time in the hospital after the gastrostomy tube was placed, and children that gained the most weight had the greater likelihood of surviving when compared with the children who did not gain weight. Other studies have also shown similar benefits (Henderson et al. 1994).

\section{Summary}

The face of paediatric HIV disease in developed countries has changed over the past 10 years. Care providers now focus on paediatric HIV disease as a chronic illness. Nutritional problems now and in the past are linked to morbidity and mortality; however, with recent advances in anti-retroviral therapies, long-term nutritional complications relating to lipid metabolism and related endocrine and cardiovascular disease need to be monitored.

\section{References}

Arpadi SM, Horlick MN, Wang J, Cuff P, Bamji M \& Kotler DP (1998) Body composition in prepubertal children with human immunodeficiency virus type 1 infection. Archives of Pediatrics and Adolescent Medicine 152, 688-693.

Berhane RAE, Aceng E, Marum L, Bagenda D, Bosch R, Ndugwa C \& Olness K (1996) Physical growth and mortality risk in children with perinatally acquired HIV. Pediatric AIDS and HIV Infection 7, 281.

Butler KM, Husson R, Lewis L, Mueller B, Gress J, Jacobsen F, Higham C, Montrella K, Jarosinski P, Balis FM, Venson D \& Henry N (1993) Pancreatitis in human immunodeficiency virusinfected children receiving dideoxyinosine. Pediatrics 91, 747-751.

Carr A, Samaras K, Burton S, Law M, Freund J, Chisholm DJ \& Cooper DA (1998a) A syndrome of peripheral lipodystrophy, hyperlipidemia, and insulin resistance in patients receiving HIV protease inhibitors. AIDS 12, F51-F58.

Carr A, Samaras K, Chisholm DJ \& Cooper DA (1998b) Pathogenesis of HIV-1-protease inhibitor-associated peripheral lipodystrophy, hyperlipidaemia, and insulin resistance. Lancet 351, 1881-1883.

Carr A, Samaras K, Thorisdottir A, Kaufman GR, Chisholm DJ \& Cooper DA (1999) Diagnosis, prediction, and natural course of HIV-1 protease inhibitor-associated lipodystrophy, hyperlipidaemia, and diabetes mellitus: a cohort study. Lancet 353, 2093-2099.

Center for Disease Control (1993) 1993 Revised classification system for HIV infection and expanded surveillance case definition for AIDS among adolescents and adults. Mortality and Morbidity Weekly Review 41, 1-19.

Centers for Disease Control, Task Force on Kaposi's Sarcoma and Opportunistic Infections (1982) Epidemiologic aspects of the 
current outbreak of Kaposi's Sarcoma and opportunistic infection. New England Journal of Medicine 306, 248-252.

Chandra RK \& Newbuerne PM (1977) Nutrition, Immunity and Infection: Mechanisms of Interactions. New York: Plenum Press.

Chlebowski RT, Grosvenor MB, Berhard NH, Morales LS \& Bulcavage LM (1989) Nutritional status, gastrointestinal dysfunction, and survival in patients with AIDS. American Journal of Gastroenterology 84, 1288-1293.

Clarick RH, Hanekom W, Yogev R \& Chadwick EG (1997) Megestrol acetate treatment of growth failure in children with human immunodeficiency virus. Pediatrics 99, 354-357.

Connor EM, Sperling RS, Gelber R, Kiselev P, Scott G, O'Sullivan MJ, VanDyke R, Bey M, Shearer W \& Jacobson RL (1994) Reduction of maternal-infant transmission of human immunodeficiency virus type- 1 with zidovudine treatment. New England Journal of Medicine 31, 1173-1180.

Dube MP, Johnson DL, Currier JS \& Leedom JM (1997) Protease inhibitor-associated hyperglycaemia. Lancet 350, 713-714.

Falloon J, Eddy J, Wiener L \& Pizzo PA (1989) Human immunodeficiency virus infection in children. Journal of Pediatrics 114, $1-30$.

Flores EA, Bistrian BR, Pomposelli JJ, Dinarella CA, Blackburn GL \& Istfan NW (1989) Infusion of tumor necrosis factor/ cachectin promotes muscle catabolism in the rat: a synergistic effect with interleukin 1. Journal of Clinical Investigation 83, 1614-1622.

Gallo RC, Salahuddin SZ, Popovic M, Shearer GM, Kaplan M, Haynes BF, Palker TJ, Redfield R, Oleske J \& Safai B (1984) Frequency, detection, and isolation of cytopathic retroviruses (HTLV-III) from patients with AIDS and at risk for AIDS. Science 124, 500-503.

Greene JB (1988) Clinical approach to weight loss in the patient with HIV infection. Gastroenterology Clinics of North America 17, 573-586.

Henderson RA, Miotti PG, Saavedra JM, Dallabetta G, Chiphangwi J, Liomba G, Taha TE \& Yolken RH (1996) Longitudinal growth during the first two years of life in children born to HIV-infected mothers in Malawi, Africa. Pediatric AIDS and HIV Infection 7, 91-97.

Henderson RA, Saavedra J, Perman JA, Hutton N, Livingston RA \& Yolken RH (1994) Effect of enteral tube feeding on growth of children with symptomatic human immunodeficiency virus infection. Journal of Pediatric Gastroenterology and Nutrition 18, 429-434.

Henderson RA, Talusan K, Hutton N, Yolken RH \& Caballero B (1997) Serum and plasma markers of nutritional status in children infected with the human immunodeficiency virus. Journal of the American Dietetic Association 97, 1377-1381.

Henderson RA, Talusan K, Hutton N, Yolken RH \& Caballero B (1998) Resting energy expenditure and body composition in children with HIV infection. Journal of Acquired Immune Deficiency Syndromes 19, 150-157.

Henry K, Rahtgaber S, Sullivan C \& McCarbe K (1992) Diabetes mellitus induced by megestrol acetate in a patient with AIDS and cachexia. Annals of Internal Medicine 116, 53-54.

Hommes MJ, Romijn JA, Endert E \& Sauerwein HP (1991) Resting energy expenditure and substrate oxidation in human immunodeficiency virus (HIV)-infected asymptomatic men: HIV affects host metabolism in the early asymptomatic stage. American Journal of Clinical Nutrition 54, 311-315.

Hughes WT, Price RA \& Sisko F (1974) Protein-calorie malnutrition: a host determinant for Pneumocystis carinii infection. American Journal of Diseases of Children 128, 44-52.

Katz MH, Mastrucci MT, Leggott PJ, Westenhouse J, Greenspan JS \& Scott GB (1993) Prognostic significance of oral lesions in children with perinatally acquired human immunodeficiency virus infection. American Journal of Diseases of Children 147, 45-48.
Kotler DP, Gaetz HP, Lange M, Klein EB \& Holt PR (1984) Enteropathy associated with the acquired immunodeficiency syndrome. Annals of Internal Medicine 104, 421-428.

Kotler DP, Tierney AR, Wang J \& Pierson RN (1989) Magnitude of body-cell-mass depletion and the timing of death from wasting in AIDS. American Journal of Clinical Nutrition 50, 444-447.

Lake-Bakaar Quadros E, Beidas S, Elsakr M, Tom W, Wilson DE, Dincsay HP, Cohen P \& Straus EW (1988) Gastric secretory failure in patients with the acquired immunodeficiency syndrome (AIDS). Annals of Internal Medicine 109, 502-504.

Mgone CS, Mhalu FS, Shao JF, Britton S, Sandstrom A, BredbergRaden U \& Biberfeld G (1991) Prevalence of HIV-1 infection and symptomatology of AIDS in severely malnourished children in Dar Es Salaam, Tanzania. Journal of Acquired Immune Deficiency Syndromes 4, 910-913.

Miller TL, Awnetwant E, Evans S, Morris VM \& Vazquez IM (1995) Gastrostomy tube supplementation for HIV-Infected children. Pediatrics 96, 696-702.

Miller TL, Evans S, Orav EJ, McIntosh K \& Winter HS (1993) Growth and body composition in children with human immunodeficiency virus-1 infection. American Journal of Clinical Nutrition 57, 588-592.

Miller TL, Evans S, Vasquez I \& Orav EJ (1997a) Dietary intake is an important predictor of nutritional status in HIV-infected children. Pediatric Research 41, 85A.

Miller TL, McQuinn L \& Orav EJ (1997b) Endoscopy of the upper gastrointestinal tract as a diagnostic tool for children with human immunodeficiency infection. Journal of Pediatrics 130, 766-773.

Miller TL, Orav EJ, Colan S \& Lipshultz SE (1997c) Nutritional status and cardiac mass and function in children infected with the human immunodeficiency virus. American Journal of Clinical Nutrition 66, 660-664.

Miller TL, Orav EJ, Martin SR, Cooper ER, McIntosh K \& Winter HS (1991) Malnutrition and carbohydrate malabsorption in children with vertically-transmitted human immunodeficiency virus-1 infection. Gastroenterology 100, 1296-1302.

Miller TL, Winter H, Luginbuhl LM, Orav EJ \& McIntosh KS (1992) Pancreatitis in pediatric human immunodeficiency virus infection. Journal of Pediatrics 120, 223-227.

Moye J, Rich KC, Kalish LA, Sheon AR, Diaz C, Cooper ER, Pitt J \& Handelsman E for the Women and Infants Transmission Study Group (1996) Natural history of somatic growth in infants born to women infected by human immunodeficiency virus. Journal of Pediatrics 128, 58-69.

National Research Council (1989) Recommended Dietary Allowances, revised ed. Washington, DC: National Academy Press.

Oster MH, Enders SR, Samuels SJ, Cone LA, Hooton TM, Browder DP \& Flynn NM (1994) Megestrol acetate in patients with AIDS and cachexia. Annals of Internal Medicine 121, 400-408.

Pitt J, Goldfarb J, Schluchter M, Kovacs A, Cooper E, Hodes D, MacIntosh K, Peavy H \& Shearer W (1998) HIV vertical transmission rate determinations are subject to differing definitions and therefore different rates. The Pediatric Pulmonary and Cardiovascular Complications of Vertically Transmitted HIV Infection Study Group. Journal of Clinic Epidemiology 51, 159-164.

Pizzo PA \& Wilfert CM (editors) (1989) In Pediatric AIDS: The Challenge of HIV Infection in Infants, Children and Adolescents, 3rd ed. Baltimore, MD: Williams and Wilkins Publishers.

Saavedra JM, Henderson R, Perman JA, Hutton N, Livingston RA \& Yolken RH (1995) Longitudinal assessment of growth in children born to mothers with human immunodeficiency virus infection. Archives of Pediatrics and Adolescent Medicine 149, 497-502. 
Scrimshaw NS, Taylor CE \& Gordon JE (1968) Interactions of Nutrition and Infection. WHO Monograph Series no. 57. Geneva: WHO.

Striker R, Conlin D, Marx M \& Wiviott L (1998) Localized adipose tissue hypertrophy in patients receiving human immunodeficiency virus protease inhibitors. Clinical Infectious Disease 27, 218-220.

Suttmann U, Ockenga L, Hoogestraat L, Selberg O, Schedel I, Deicher H \& Muller MJ (1993) Resting energy expenditure and weight loss in human immunodeficiency virus-infected patients. Metabolism 42, 1173-1179.

The European Collaborative Study (1995) Weight, height, and human immunodeficiency virus infection in young children of infected mothers. Pediatric Infectious Diseases Journal 14, 685-690.

The Italian Pediatric Intestinal/HIV Study Group (1993) Intestinal malabsorption of HIV-infected children: relationship to diarrhea, failure to thrive, enteric micro-organisms and immune impairment. AIDS 7, 1435-1440.

Ullrich R, Zeitz M, Heise W, L'age M, Hoffken G \& Riecken EO (1989) Small intestinal structure and function in patients infected with human immunodeficiency virus (HIV): Evidence for HIV-induced enteropathy. Annals of Internal Medicine 111, $15-21$.

von Roenn JH, Murphy RL, Weber KM, Williams LM \& Weitzman SA (1994) Megestrol acetate in patients with AIDSrelated cachexia. Annals of Internal Medicine 121, 393-399.

Yolken RH, Hart W, Oung I, Schiff C, Greenson J \& Perman JA (1991) Gastrointestinal-dysfunction and diasaccharide intolerance in children infected with human immunodeficiency virus. Journal of Pediatrics 118, 359-363.

Zuin G, CD, Fontana M (1994) Energy and nutrient intakes in HIV-infected children. Pediatric AIDS and HIV Infection 5, $159-161$. 